\title{
An Effective Quality of Experience Measurement and Calculation Method for IPTV Service
}

\author{
Liu Jing, Sunyoung Han ${ }^{1}$, Li Xuan, Han Li and Sungchol Cho \\ The Department of Computer Science and Engineering Konkuk University, 1 \\ Hwayang, Gwangjin, Seoul 143-701, Korea \\ jing8100@gmail.com,syhan@cclab.konkuk.ac.kr, \\ lixun@cclab.konkuk.ac.kr,hanli@cclab.konkuk.ac.kr,cschol@cclab.konkuk.ac.kr
}

\begin{abstract}
This study focuses on the topics of Quality of Experience which is essentially focused on business users feeling. The purpose of $Q o E$ is to realize the user-centered management. QoE is how to come up from the Angle of the user service analyze network service. QoE regards the network service as one unity and considers the various aspects of affecting the network service performance. However by comparison, QoS only pays attention to the network performance which means QoS is one subset of QoE. At present, the difficulty and key point of the study about QoE is how to quickly and effectively compute the indexes which influence QoE. In this paper, in order to solve this problem, we proposed a solution to compute the indexes which influence the QoE result by using the AHP algorithm. And we did an experiment with the real users 'participation in the laboratory which proved that this solution is correct and practicable. It can reflect the QoE result of real end users and provide a valuable reference for the contents provider, ISP and the end service provider about how to provide more stable and higher-quality service.
\end{abstract}

Keywords: Quality of Experience, Quality of Service, Measurement, Index of satisfaction

\section{Introduction}

Along with a tremendous development in computer and network technology, Services have become abundant and therefore ISP competition is becoming more and fiercer. In order to stand successfully, ISPs must gain the recognition from customers for their services. Therefore, they eagerly need an evaluating standard which is based on the acceptance of customers. SoQoS(Quality of Service) [1] was the most popular standard that was adopted. The main evaluating index of QoS was the network throughput, time latency, PLP, jitter, BER and so on [3]. Apparently, these only reflected the technical performance of services, even more only in network transport layer, but neglecting the actual customers' experience, then QoS could not be the direct measurement of customers' feedback. Consequently, QoE, (Quality of Experience) [4-7] which was an evaluation concept that could reflect the customer actual requirements, was proposed. It synthesized effects of service, customer and environment, thereby could reflect the recognition of the customer.

QoS was the main consideration in convention of telecom and computer network. It was initially defined as a synthesized result which was decided by customer service satisfaction. It made the provision of best service to customer as the final purpose. Considering customers' different requirements, it needed to define a group of public parameters for the low layer

${ }^{1}$ Corresponding author 
protocol. Therefore, QoS was considered as data transmit index of low layer, such as time latency, jitter, band width, and BER. The concept of QoS defined by ITU-T initially mapped the one of QoE. The mechanism of QoS was managing and providing the differences on point of view of network services and qualities of network. But from view of customer, QoE had a wider and more subjective concept. From the view of a mobile telecom network, the best solution of QoE was the best service of QoS from End to End [4].

The research of QoE is mainly divided into the following parts: the definition and effective element of QoE, the measurement of QoE, the evaluating index of QoE, the evaluating methodology, and the optimized simulation model of QoE. Because QoE included service, customer, and environment, and also the different requirements from customers, it brought a big challenge for the research of QoE. First of all, the research of QoE needed the theory of computer science, psychology, sociology, and statistics. Secondly, it was difficult to be quantitation of parts of index of QoE. For example, effectiveness of the subject of the customer and environment; thirdly, it could not create a unified model for different services. Consequently, the current research of QoE had the following characteristics: (1). Due to the difficult quantitation towards the effect of subject of customers and of the environment, we were mainly focused on the research of service. (2) The evaluation index of QoE was distributed to different layers. In addition, most of the research of the evaluation method was on the network and application layer. There was a lack of research on customer satisfaction of service? (3).The evaluation index of QoE was still on the specific service, and the difference of index of different services was often too much. (4) The theory of QoE was not mature and had many different quantitation methods and evaluations. (5). Most of the research on QoE was focused on Video and Audio service.

In order to give a precise measurement of QoR, we would compute the effective elements of QoE by using the AHP mechanism. In the following section we would introduce AHP. The complex decision of environment would be divided into several parts by AHP, and then a hierarchical structure with different weights and priorities would consist of these parts.

We would use AHP to calculate the evaluating index, and then analyze the effect. AHP could solve the multiple layers issue of many indexes, but it also has some drawback. It must be based on mature experience of experts of different aspects. Therefore, in order to better use AHP, basing on several research results, we had indicated the importance of the effectiveness of different index by synthesizing them, and calculated the actual influence.

We had built an experiment to evaluate the accuracy of QoE index. We did this by establishing the network testing environment and using the overlay network to transport the Video files which could get the same broadcasting quality and status for End to End.

By compressing the same video files in different ways, using different end users, and by using different QoE environments to do the experiment, we were left with several different groups of data.

Consequently, after analyzing the satisfaction of the customer toward the video broadcast, we got the similar results. This verified the proposed AHP correctness and reality.

In Section 2 of this paper, we introduced the AHP definition and effective elements and weights which could affect QoE; in Section 3, we described the establishment of experiment environments and measurement, and worked out the result; in Section 4, we analyzed the experiment result, and proved our AHP accuracy as being reality. In the final part, we had summarized this paper and proposed future research. 


\section{AHP Algorithm Introduction \& QOE Parameters Determination}

The AHP mechanism was proposed by Professor Thomas L. Saaty. It was suitable for being used as the decision which was based on multiple valuating standards. Hierarchal AHP was the most popular and adopted one.

The criteria, weight, and analysis which were consisted of hierarchy could help the decision maker to better understand the target. Besides, AHP could help to coordinate the subjective and objective [evaluation standard], evaluate the consistent and alternative plan, and then decrease the mistake. The issue would be divided into different evaluation but still keep the whole decision strategy.

AHP's characteristics:

It's simple and clear, which means it could help decision-maker to make his thoughts methodical, quantitative and easier to compute. And it only needs less quantitative data to analyze the innately character and relationship of the issue more deeply.

AHP's disadvantage:

It had a big randomness, for same question, if on the condition of no interrupting, and influences, different people use same AHP, then the built hierarchy model and valuating matrix and analyzed result would be different.

In order to conquer the drawback, in reality, specially being on the condition of multiple targets, multiple standards, multiple elements, and multiple layers, the issue establishment that could be affected by kinds of element and hierarchy model, usually need the cooperation which came from different area experts and decision. While creating evaluation matrix, the judgment of importance of different elements also need different opinions, such as, the average, mode, and median.

\subsection{QoE Parameters Determination}

In this section, we had researched several methods which could affect QoE. In the conventional research, they were mainly focused on guaranteeing the QoS, but the standard of measuring the network and service was based on QoE. It could reflect the system performance on the point of view of end-user, therefore the research of index of QoE was more practical. In the meantime, QoE and QoS had a tighter relationship. In other words, QoE was mainly decided by QoS, but not only by QoS. It was also decided by users, service type, user's expectation, specific service according to different conditions, and environment index which were accepted by end-user. So as Figure 1 show, our proposal had added two effective factors into AHP mechanism besides QoS.

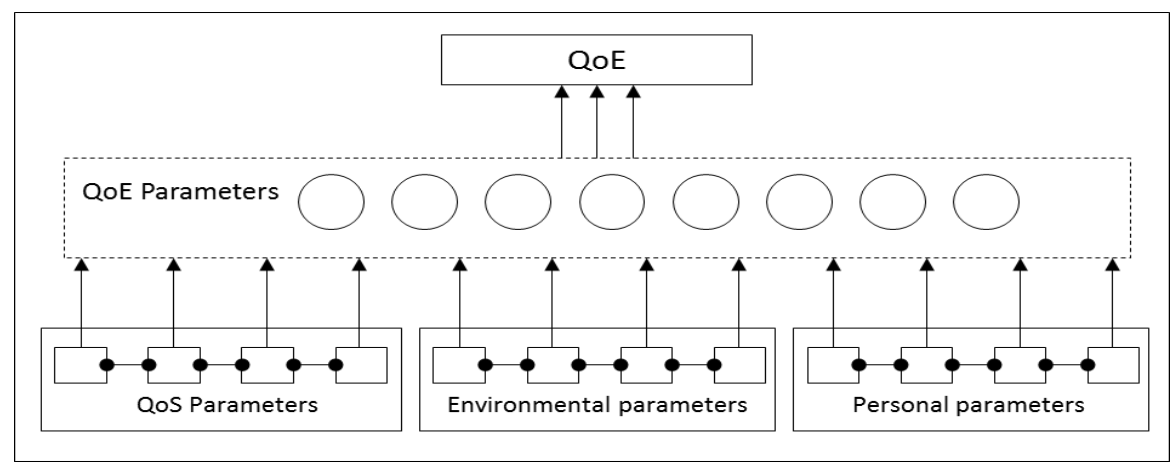

Figure 1. Three Parts of QoE 
Finally, we had determined the following 3 aspects and 28 indexes:

Table 1. Impact Indexes of QoE

\begin{tabular}{|c|l|l|}
\hline Qos Parameters(QP) & $\begin{array}{c}\text { Environmental } \\
\text { Parameters(PP) }\end{array}$ & $\begin{array}{c}\text { Personal } \\
\text { Parameters(EP) }\end{array}$ \\
\hline One-Way Delay & Age & $\begin{array}{c}\text { Service Runtime } \\
\text { Environment }\end{array}$ \\
\hline Round-Trip Delay & Gender & Noise Size \\
\hline Transmission Delay & Personal Preferences & Lighting Conditions \\
\hline Propagation Delay & Educational Background & $\begin{array}{c}\text { Fixed or Mobile } \\
\text { Environment } \\
\text { Social and Cultural } \\
\text { Environment }\end{array}$ \\
\hline Exchange Delay & Life Experiences & \\
\hline $\begin{array}{c}\text { Instantaneous Packet } \\
\text { Delay Variation }\end{array}$ & Expectations & \\
\hline Packet Loss Rate & Physical \& Mental State & \\
\hline Bottleneck Bandwidth & & \\
\hline Throughput & & \\
\hline Link Utilization & & \\
\hline Service Availability & & \\
\hline Host Availability & & \\
\hline Network Availability & & \\
\hline $\begin{array}{c}\text { Instantaneous Route of } \\
\text { a Network Path }\end{array}$ & & \\
\hline Available Bandwidth & & \\
\hline
\end{tabular}

In Table 1, according to QP (Qos Parameters), EP (Environmental Parameters), PP (Personal Parameters), we merge the similar indexes. For example one-way delay, Round-trip delay, Transmission delay, exchange delay, Propagation delay in column QP, we unified them as delay indexes same as Table 2 .

Table 2. The Combined Indexes

\begin{tabular}{|c|c|c|}
\hline QP & PP & EP \\
\hline Delay & Age & Noise \\
\hline Packet Loss Rate & Gender & $\begin{array}{c}\text { Lighting } \\
\text { Conditions }\end{array}$ \\
\hline $\begin{array}{c}\text { Available } \\
\text { Bandwidth }\end{array}$ & Expectations & $\begin{array}{c}\text { Fixed or } \\
\text { Mobile } \\
\text { Environment }\end{array}$ \\
\hline Jitter & $\begin{array}{c}\text { Physical and Mental } \\
\text { State }\end{array}$ \\
\hline
\end{tabular}

\subsection{AHP Algorithm Calculation}

Based on the AHP, we had calculated several indexes which could affect QoE. Because AHP needs the subjective experience of experts, in order to better use the AHP mechanism, 
we have referenced many research results which could affect the importance of indexes of QoE. After summarizing, we had done the calculation of indexes which were based one AHP.

Based on the standard of the elements of the parent layer, the same layer elements are compared by pair. According to the evaluation rule, we could determine the relative importance of the indexes, and establish the judging matrix. As Figure 2 shows.

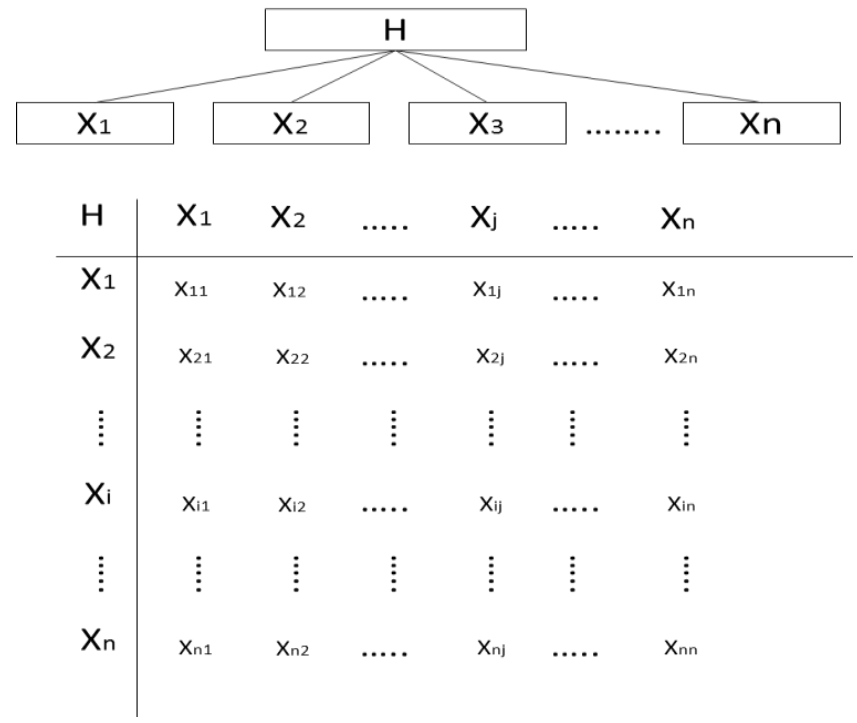

Figure 2. AHP Judgment Matrix Algorithm

$\mathrm{Xij}$ was the importance which considered $\mathrm{Xi}$ to $\mathrm{Xj}$ on the point of view of judging rule $\mathrm{H}$. suppose in rule of $\mathrm{H}$, elements $\mathrm{Xl}, \mathrm{X} 2, \ldots, \mathrm{Xn}$ 's weights were $\mathrm{Xi} / \mathrm{Xj}$, as Figure 3 shows, we called it as judge matrix. Then $\mathrm{Xii}=1 ; \mathrm{Xij}=1 / \mathrm{Xji}$ were elements of matrix, $\mathrm{Xij}$ was the quantity rule which indicated the relative importance of two elements, as the judge rule, their values as Table 3 shows.

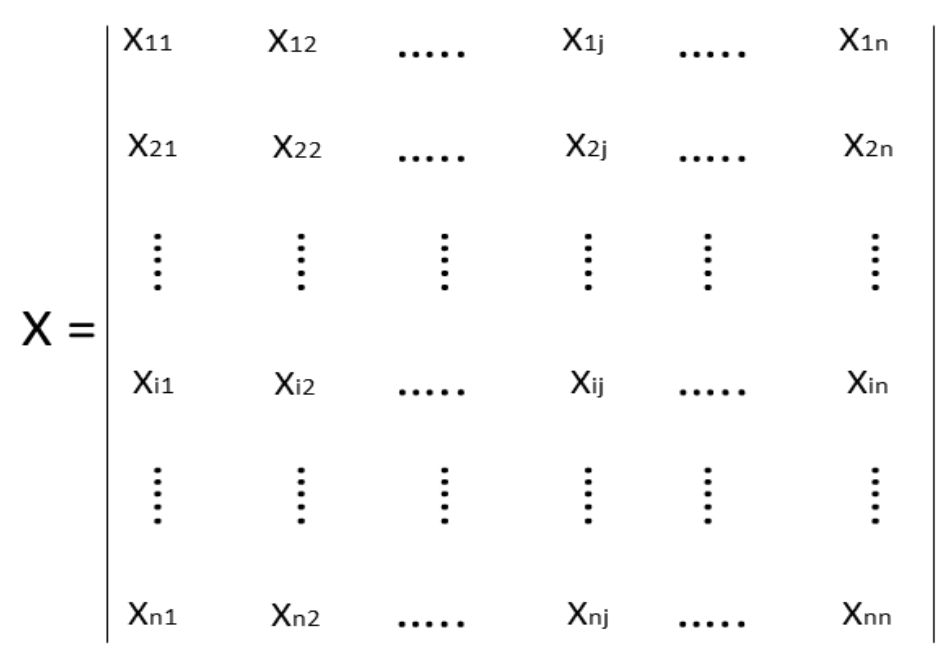

Figure 3. AHP Algorithm Calculation Process 
Table 3. AHP Algorithm Judgment Dimension Definition Table

\begin{tabular}{|c|c|c|c|}
\hline $\begin{array}{l}\text { Determine } \\
\text { scale }\end{array}$ & Definition & $\begin{array}{l}\text { Determine } \\
\text { scale }\end{array}$ & Definition \\
\hline 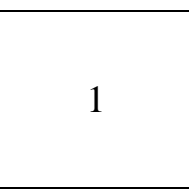 & $\begin{array}{c}\text { I and } \mathrm{J} \\
\text { Factors are } \\
\text { Equally } \\
\text { Important }\end{array}$ & 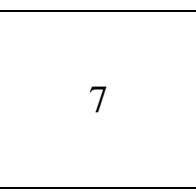 & $\begin{array}{l}\mathrm{i} \text { is very } \\
\text { important than } \mathrm{j} \\
\text { factors }\end{array}$ \\
\hline 3 & $\begin{array}{c}\text { I Factor is a } \\
\text { Little Important } \\
\text { than j Factor }\end{array}$ & 9 & $\begin{array}{l}\mathrm{i} \text { is absolutely } \\
\text { important factors } \\
\text { than } \mathrm{j}\end{array}$ \\
\hline 5 & $\begin{array}{l}\text { I factor is } \\
\text { more Important } \\
\text { than J Factors }\end{array}$ & $2,4,6,8$ & $\begin{array}{c}\text { is the } \\
\text { intermediate state } \\
\text { between the two } \\
\text { numerical }\end{array}$ \\
\hline
\end{tabular}

\subsection{AHP Algorithm Calculation Results}

The calculated results which were based on AHP as showing in Figure 4; the percent of QP in QoE was 80.84\%. In other words, the influence of QoS to the whole QoE system was the most, and so were the weights. The other two indexes, EP were $11.76 \%$, and PP was $7.40 \%$.

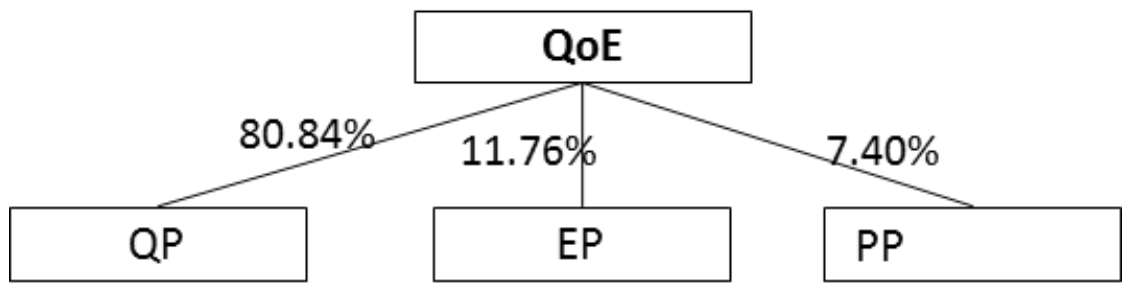

Figure 4. Proportion of Three Classes

With same method to calculate the QP, EP, and PP, the weights as Figure 5 show.

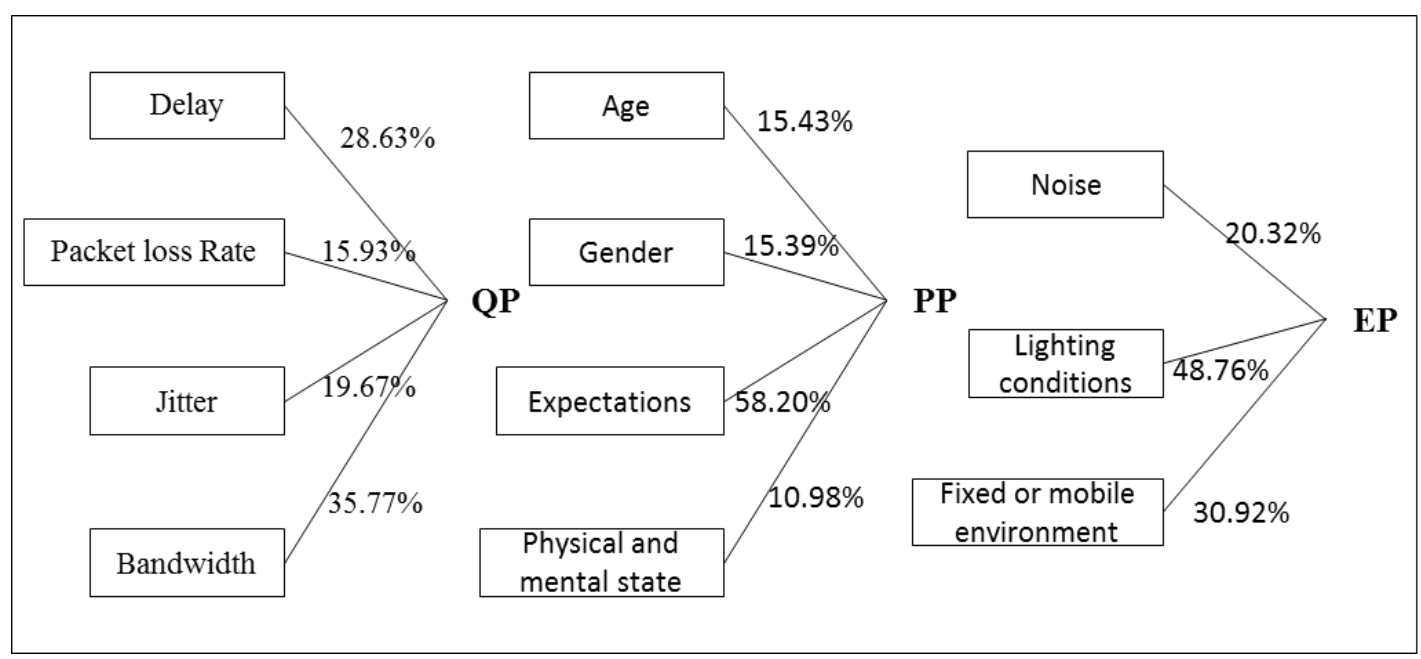

Figure 5. Under the Three Categories of each Index Proportion 
Through this method, then combining QP, EP, PP's weights, we had worked out all of the indexes' weight ratios, as Table 4 showed

Table 4. The Weight of all Index of QoE

\begin{tabular}{|c|c|c|c|c|c|}
\hline Delay & $\begin{array}{c}23.14 \\
\%\end{array}$ & Age & $\begin{array}{c}15.43 \\
\%\end{array}$ & Noise & $20.32 \%$ \\
\hline Loss & $\begin{array}{c}12.88 \\
\%\end{array}$ & Gender & $\begin{array}{l}15.39 \\
\%\end{array}$ & $\begin{array}{c}\text { Lighting } \\
\text { conditions }\end{array}$ & $48.76 \%$ \\
\hline Jitter & $\begin{array}{c}15.90 \\
\%\end{array}$ & $\begin{array}{c}\text { Expectati } \\
\text { ons }\end{array}$ & $\begin{array}{c}58.20 \\
\%\end{array}$ & $\begin{array}{c}\text { Fixed or } \\
\text { mobile } \\
\text { environment }\end{array}$ & $30.92 \%$ \\
\hline $\begin{array}{c}\text { Bandwid } \\
\text { th }\end{array}$ & $\begin{array}{c}28.92 \\
\%\end{array}$ & $\begin{array}{c}\text { Physical } \\
\text { and mental } \\
\text { state }\end{array}$ & $\begin{array}{c}10.98 \\
\%\end{array}$ & - & - \\
\hline
\end{tabular}

\section{QoE Network Design}

\subsection{The Design of QoE Test Network}

We would use experiment to evaluate the accuracy and feasibility of QoS index. Due to the difficulty of establishing the experiment environment of EP and PP, and their percent in QoE was not up to $20 \%$, in the real experiment, we ignored the effect of EP and PP to QoE. Meanwhile in order to get precise results, we only had done the experiment for QP.Thenit describes the environment of experiment of QP, and the evaluation of index.

This test-bed architecture is going to be built based on the advantage of multicast on the overlay multicast network. We will explain the procedure via unicast traffic and multicast traffic. If the video is transmitted by unicast, the starting time of receivers watching the video is different with each other. Through multicast transmission, the video will be displayed to all receivers at the same time. So in our test-bed, in order to get more exact and objective test results, we select the multicast transmission way to send the video.

The test-bed architecture for QoE framework consists of 3 parts as figure 6 shows: Server Side, Client Side and the overlay multicast network connecting both sides.

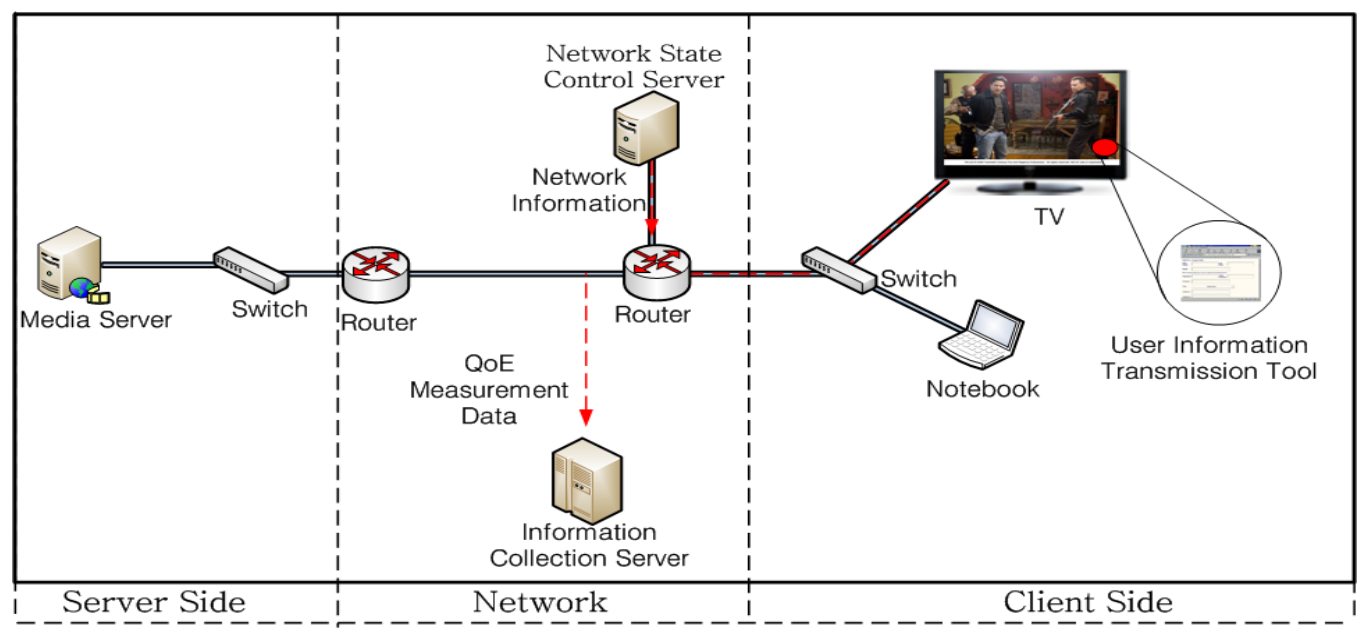

Figure 6. The Test Bed Structure 
On the server side, the media server and contents-providing device are built to transmit the test video sample by multicast way.

On the client side, the TV and monitor are prepared to receive the contents and forward them to all of users.

The overlay multicast network part is consisted like this: the bandwidth or other network metrics can be controlled between the two routers by the Network State Control Server, and the QoE test data is sent to and saved on the Information Collection Server.

For efficient and convenient QoE measuring, we made a one-button tool [8] on the users' PCs. When the user becomes dissatisfied with QoE of the video, he can click the button. Then the objective QoS parameters and the subjective QoE application parameters will be saved into the Information Collection Server.

\subsection{Introduction of QoE Test Bed}

In this section, we are going to introduce the function of each part in the whole test network.

Media Server: it's for saving and transmitting the test contents sample. The contents sample includes network measurement contents and application parameter's contents. Each kind of contents sample has SDTV and HDTV 2 levels.

Router: the device which is responsible for the packets overlay multicast transmission.

Information Collection Server: when users click the button with the unsatisfied experience, the time and QoE parameter information will be sent and saved onto Information Collection Server by the measurement tool.

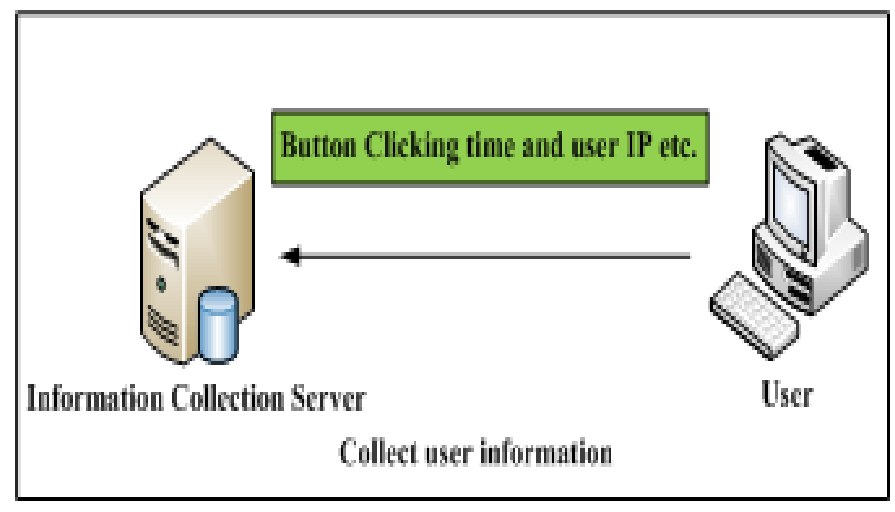

Figure 7. Information Collection Server

Network State Control Server: when users click the buttonwith the unsatisfied experience, the bandwidth, delay, loss rate, jitter information of the network will be saved. While the QoE parameters are measured, Network State Control Server is able to increase the background load, and manage the bandwidth, delay, loss rate, jitter parameters of network in real time.

TV: the test video is displayed on it, and users express the unsatisfied experience via the measurement tool after watching the video.

Measurement Tool Figure 8, 9: when users become dissatisfied with the video or audio, they will express their unsatisfying experience by clicking the button on the measurement tool. Then the information will be saved onto the Information Collection Server. 


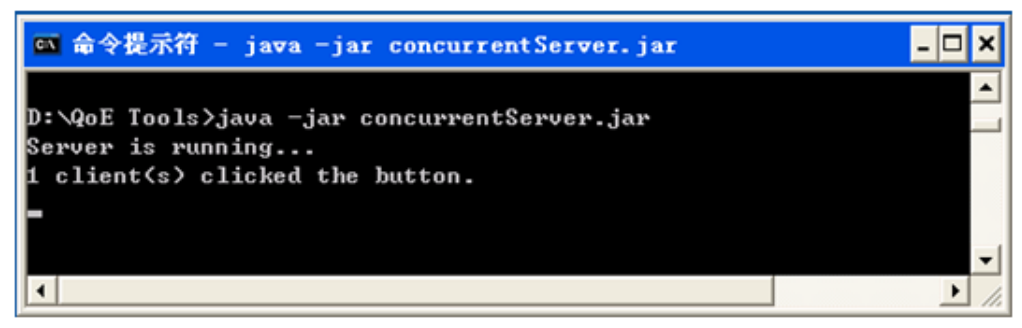

Figure 8. Collect Information

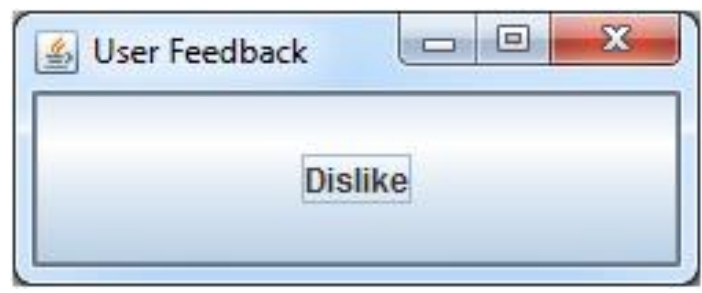

Figure 9. Information Collection Tool

\section{Experiment in the QoE Network Test-Bed}

In this section, we are going to discuss how to compare and analyze the data of the test result. Firstly, we will explain how to use these data. Then we will combine the Group Difference Average Method and Group Successive Difference Average Method to compute the rate of change of users' satisfaction. At last, this rate of change computed should be compared with the percentage computed by AHP algorithm.

\subsection{The Experimental Process}

First, in order to define the whole value range of QoS, we should get 4 value ranges by fixing 3 of 4 parameters with adjusting the other one and recording the value range that reflects the amount of unsatisfied user from $0 \%$ to $100 \%$. As shown in Table 5, we select SD level video as the test video source.

Table 5. Value Range of Indexes

\begin{tabular}{|c|c|c|c|c|c|c|}
\hline \multicolumn{7}{|c|}{ SDTV Compressing Format } \\
\hline $\begin{array}{c}\text { QoE } \\
\text { Level }\end{array}$ & $\begin{array}{c}\text { Lev } \\
\text { el }\end{array}$ & $\begin{array}{c}\text { Percentag } \\
\text { e of } \\
\text { dissatisfied }\end{array}$ & $\begin{array}{c}\text { Bandwidt } \\
\mathbf{h} \\
(\mathbf{M b})\end{array}$ & $\begin{array}{c}\text { Del } \\
\mathbf{a y} \\
(\mathbf{m s}\end{array}$ & $\begin{array}{c}\text { Los } \\
\mathbf{S} \\
(\boldsymbol{\%})\end{array}$ & $\begin{array}{c}\text { Jitt } \\
\mathbf{e r} \\
(\mathbf{m s})\end{array}$ \\
\hline Excellen & 1 & $0 \%$ & $1.295-$ & - & - & -52 \\
$\mathrm{t}$ & & $-5 \%$ & & 2560 & 0.19 & \\
\hline Good & 2 & $5 \%$ & 1.277 & 256 & 0.1 & 52 \\
& & $-15 \%$ & -1.295 & 0 & 9 & -58 \\
& & & & - & - & \\
\hline Normal & 3 & $15 \%$ & 1.24 & 261 & 0.2 & 58 \\
& & $-30 \%$ & -1.277 & 3 & 2 & -65 \\
\hline
\end{tabular}




\begin{tabular}{|c|c|c|c|c|c|c|}
\hline & & & & - & - & \\
\hline Poor & 4 & $30 \%$ & 1.22 & 266 & 0.2 & 65 \\
& & $-50 \%$ & -1.24 & 5 & 7 & -92 \\
& & & & - & - & \\
& & & & 2960 & 0.29 & \\
\hline $\mathrm{Bad}$ & 5 & $50 \%-$ & -1.22 & 296 & 0.2 & $92-$ \\
& & & & $0-$ & $9-$ & \\
\hline
\end{tabular}

For measuring the KPI parameters, about 50 end users are selected to watch the same video at the same time. When the level of one KPI is measured, the other 3 KPIs should be kept in the optimal state. Then the satisfaction rate of users can be measured while the variable KPI is adjusted continually.

Table 6. An Example of QoE Percentage Recording

\begin{tabular}{|c|c|c|c|c|c|c|c|}
\hline \multicolumn{8}{|c|}{ Delay 1} \\
\hline & \multicolumn{4}{|c|}{ Bandwidth 1} & \multicolumn{3}{|c|}{ Bandwidth 2,3,4 } \\
\hline & $\begin{array}{c}\text { Jitter } \\
1\end{array}$ & $\begin{array}{c}\text { Jitter } \\
2\end{array}$ & $\begin{array}{c}\text { Jitter } \\
3\end{array}$ & $\begin{array}{c}\text { Jitter } \\
4\end{array}$ & $\begin{array}{c}\text { Jitter } \\
1\end{array}$ & $\begin{array}{c}\text { Jitter } \\
2\end{array}$ & - \\
\hline $\begin{array}{c}\text { Loss } \\
1\end{array}$ & $0 \%$ & $5 \%$ & $10 \%$ & $20 \%$ & $10 \%$ & - & - \\
\hline $\begin{array}{l}\text { Loss } \\
2\end{array}$ & $5 \%$ & - & - & - & - & - & - \\
\hline $\begin{array}{l}\text { Loss } \\
3,4\end{array}$ & $10 \%$ & - & - & - & - & - & - \\
\hline
\end{tabular}

As shown in Table 5, we fix 3 parameters at a specific value and adjust the other one, and then we can get 5 values of user's unsatisfied rate which are recorded in Table 6 by percentage way. For example, when the delay, bandwidth and loss are at 1 level which means the most excellent state, the values of 3 parameters are respectively less than $2560 \mathrm{~ms}$, more than $1.295 \mathrm{Mb}$ and less than $0.19 \%$. Then we adjust the value of jitter from $52 \mathrm{~ms}$ to $92 \mathrm{~ms}$ and finally we record the percentage of the users' unsatisfied rate which is $0 \%, 5 \%, 10 \%$ and $20 \%$.

\subsection{The Experiment Results Analysis}

In this section we discuss the analysis on the output data from the experiment. Firstly, we will explain how the output data from the experiment is used in the analysis. We achieve the variation rate of the end user satisfaction by calculating on the experiment raw data utilizing Group Difference Average Method and Group Successive Difference Average Method. We also perform the comparison between the variation rate achieved from the experiment and that obtained from calculation using AHP algorithm.

According to the test approach described in Section 4.1, we would perform 625 test times since there were four indicators each of which had five states (i.e., $54=625$ ). We simplify the testing by removing the bad state from each indicator. Because it is obvious that the end user 
choice is unsatisfactory if all indicators are in the bad state. These results in 256 test times computed from four indicators with four statuses for each indicator (i.e., $44=256$ ).

In this part, we describe Group Difference Average Method and compute the variation rate of QoE dissatisfaction level of each indicator using this method. The value of each indicator obtained from the experiment is denoted by A<indicator number> (i.e., A1 A2 A3 A4). The indicator values of the experiment are in ascending order, which is $\mathrm{A} 4>\mathrm{A} 3>\mathrm{A} 2>\mathrm{A} 1$. There are three difference values between two adjacent indicator values: A4 - A3, A3 - A2, A2 - A1. $\mathrm{R}$ denotes the variation rate (i.e., the average of the three difference values). From equation 1 we can conclude that the variation rate of A1 A2 A3 A4 is in direct proportion to the variation rate of A1 and A4, which reduces precision. Therefore, we improved the precision of the variation rate by adopting Group Successive Difference Average Method shown in formula 2 of figure 10. Since the background usage of the experiment environment built upon the lab network has influence to the overall network performance, some data are not able to obtain using Group Successive Difference Average Method. In this case, we decide to use Group Difference Average Method to calculate the variation rate with lower precision.

$$
\begin{aligned}
& \mathrm{R}_{1}=\frac{\left(A_{4}-A_{3}\right)+\left(A_{3}-A_{2}\right)+\left(A_{2}-A_{1}\right)}{3}=\frac{A_{4}-A_{1}}{3} \\
& \mathrm{R}_{2}=\frac{\left(A_{4}+A_{3}\right)-\left(A_{2}+A_{1}\right)}{4}
\end{aligned}
$$

Figure 10. Calculation Rate Formula

The final output of the experiment is shown in Figure 11 and Table 7. The comparison of output from experiment and AHP algorithm shows that the difference between these two sets of data is not significant.

Table 7. The Comparison of AHP Result and Experimental Result

\begin{tabular}{|c|c|c|}
\hline & $\begin{array}{c}\text { The proportion obtained by } \\
\text { AHP }\end{array}$ & $\begin{array}{c}\text { The proportion obtained by } \\
\text { Experimental }\end{array}$ \\
\hline Bandwidth & $35.77 \%$ & $33.15 \%$ \\
\hline Delay & $28.63 \%$ & $30.33 \%$ \\
\hline Loss & $15.93 \%$ & $18.06 \%$ \\
\hline Jitter & $19.67 \%$ & $18.47 \%$ \\
\hline
\end{tabular}

Taking into account the influence of background data usage of the experiment network, the insignificant difference between the two sets of data can be ignored. Therefore, can conclude that the experiment result conforms to the AHP calculated result and the QoE testing indicators and the equations defined in this paper are correct as well. 


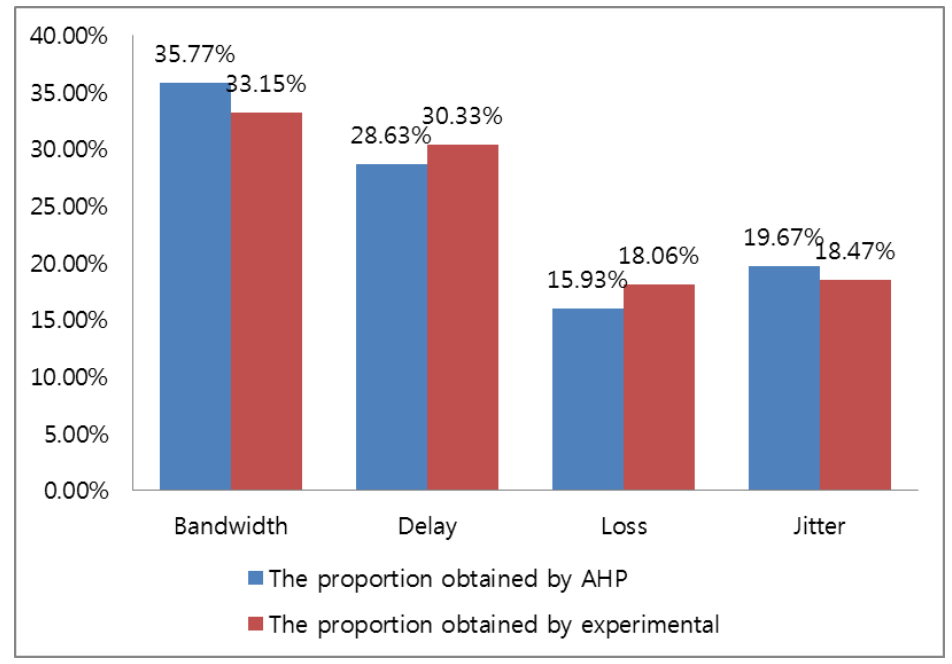

Figure 11. Graphical Compare Two Results

\section{Conclusion}

In this paper, we focused on the QoE research, particularly QoE of video streams. The research extends the consideration of network QoE factor to the environment and human background.

The paper also considered the various aspects of QoE factors, including network environment, the video receiving condition and the personal background of the end users. We analyzed the significance of those factors using the famous statistics algorithm, namely AHP to calculate proportion of each factor in the overall QoE assessment system. Due to the restrictions of experiment environment and cultural background, we only took into account the network QoS indicators. We defined experimental network environment, function of each part, and a series of experiment process to obtain sufficient lab raw data. We also analyzed and compared the result obtained from the experiment and the result calculated by the AHP algorithm to conclude that the AHP algorithm calculated indicator weight conforms to the actual situation.

Although we put a great amount of efforts to this work, we still have many issues left for the future works. Environmental and humane factors need to be considered for the indicator variation. Each indicator's weight should be further analyzed so that the key indicators of QoE could automatically adjust and modify the related indicators to improve the service quality. The contributions to the QoE research will have the network service providers provide more reliable and quality services as well as connecting service providers, contents providers and terminal providers to realize endto-end QoE management process and establish user-centric service management architecture and improve interactive architecture for management hierarchy of user, market, and maintenance of user QoE.

\section{References}

[1] F. Agboma and A. Liotta, "QoE-aware QoS management", Linz, Austria, (2008), pp. 111-116.

[2] F. Agboma, M. Smy and A. Liotta, "QoE analysis of a peer-to-peer television system", Amsterdam, Netherlands, (2008), pp. 114-119. 
[3] CISCO SYSTEM, "Internetworking Technologies Handbook", Chapter 49, Quality of Service Networking, Prentice-Hall, (2000), pp. 49-1.

[4] ITU-T Recommendation G.1080, Quality of Experience requirements for IPTV services.

[5] ITU Telecommunication Standardization Sector (ITU-T). Objective Perceptual Multimedia Video Quality Measurement in the Presence of a Full Reference, ITU-T Recommendation J.247, (2008).

[6] DSL-Forum. Triple-play Services Quality of Experience (QoE) Requirements, Technical Report TR-126, (2006), [R/OL]. http://www.broadbandforum.org/technical/download/TR-126.pdf.

[7] The Alliance for Telecommunications Industry Solutions (ATIS). A Framework for QoS Metrics and Measurements Supporting IPTV Services, ATIS-IIF, ATIS-0800004, (2006).

[8] K.-T. Chen, C.-C. Tu and W.-C. Xiao, "OneClick: A Framework for MeasuringNetwork Quality of Experience”, INFOCOM 2009, IEEE, (2009) April, pp. $702-710$.

[9] A. Khan, L. Sun and E. Ifeachor, "Impact of Video Content on Video Quality for Video over Wireless Networks", Proceeding of ICAS '09 Proceedings of the 2009 Fifth International Conference on 295 Autonomic and Autonomous Systems, Valencia, (2009) April, pp.277-282.

[10] Y. Du, W.-A. Zhou, B. Chen, J.-D. Song and Y. Du, "A QoE based Evaluation of service quality in wireless communication Network", 2009 International Conference on New Trends in Information and Service Science, (2009) July, pp. 552-557.

[11] J. Sterle, M. Volk, U. Sedlar, J. Bester and A. Kos, "Application-Based NGN QoE Controller", IEEE Communications Magazine, (2011) January, pp. 92-101.

[12] T. Hoßfeld, C. Keimel, M. Hirth, B. Gardlo, J. Habigt, K. Diepold, P. T. Gia, "Best Practices for QoE Crowdtesting:QoE Assessment with Crowdsourcing", IEEE Transactions on Multimedia, (2012) November.

[13] Y. Gong, F. Yang, L. Huang and S. Su, "Model-based Approach to Measuring Quality of Experience", 2009 First International Conference on Emerging Network Intelligence, (2009) October, pp. 29 - 32.

[14] N. Ping, J.-X. Liao, X.-M. Zhu and W. Li, "A Method of QoE mapped to SLA Based on QoS ", Journal of Electronics \& Information Technology, vol. 32, no.6, (2010) June, pp. 1463 - 1468.

[15] K. U. R. Laghari, N. Crespi, B. Molina, C. E. Palau, "QoE aware Service Delivery in Distributed Environment", Advanced Information Networking and Applications (WAINA) 2011 on IEEE Workshops of International Conference, (2011) March, pp. 837 - 842.

[16] W. Wu, M. A. Arefin, R. Rivas, K. Nahrstedt, R. M. Sheppard and Z. Yang, "Quality of Experience in Distributed Interactive Multimedia Environments: Toward a Theoretical Framework", MM '09 Proceedings of the 17th ACM international conference on Multimedia, (2009) October, pp. 481-490.

[17] H. A. Tran, A. Mellouk and S. Hoceini, "User to User adaptive routing based on QoE", ICNS 2011: The Seventh International Conference on Networking and Services, (2011) April, pp.39 - 45.

[18] ITU-T Recommendation P.10/G.100 Amendment, Vocabulary for performance and quality of service.

[19] ITU-T Recommendation G.107, the E-model: a computational model for use in transmission planning.

[20] ITU-T Recommendation G.1010, End-User multimedia QoS categories series G: Transmission Systems and Media, Digital Systems and Networks Quality of Service and Performance.

[21] ITU-T Recommendation G.1050, Network model for evaluating multimedia transmission performance over Internet Protocol

[22] ITU-T Recommendation G.1081, Performance monitoring points for IPTV.

[23] ITU-T Recommendation G.KPI, KPIs for quality management and assurance.

[24] ITU-T Recommendation G.OMVAS, opinion model for video streaming applications.

[25] ITU-T Recommendation G.RQAM, reference guide to QoE assessment methodologies.

\section{Authors}

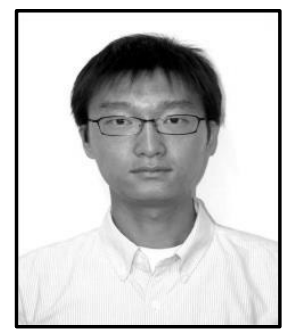

Liu Jing, he received his Bachelor's degree inComputer Technology (2006) from Keimyung Universityand his M.S. degree in Computer Networking from Konkuk University(2008). His main research interests are MobileNetwork,QoSMulticast Routing and QoE. 


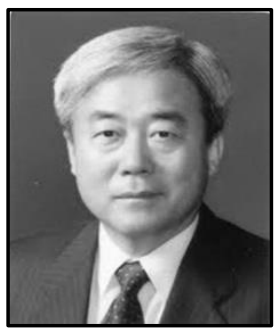

Sunyoung Han, he received the M.S. and $\mathrm{Ph} . \mathrm{D}$. degrees in Computer Science from Korea Advance Institute of Science \& Technology in 1979 and 1988, respectively. Since 1981-March, he has been working in Dept. of Computer Science \& Engineering in Konkuk University as a Professor. He was invited to University of Maryland, USA as Visiting Professor in 1989 and 1998, respectively. His research area is on Internet, Mobile IP, Multicasting, Wireless/Mobile Networks, and Future Internet.

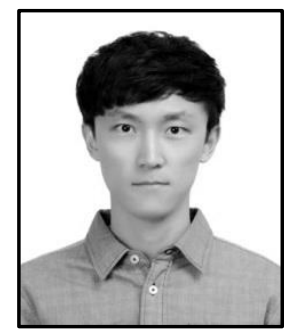

Li Xuan, he received his M.S. degree in Information and Computer Communication Engineering (2012) from Konkuk University. His current research interests include Quality of Service and Quality of Experience Measurement.

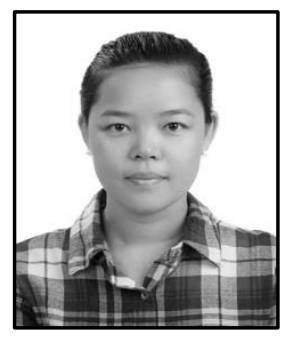

Han Li, received the M.S. degree in Computer \& Information Communication Engineering, from Konkuk University in 2012. Now she is studying as a Ph.D. student in Dept. of Computer \& Information Communication Engineering, Konkuk University. Her research area is on QoS/QoE, IPv6, mSCTP and Future Internet.

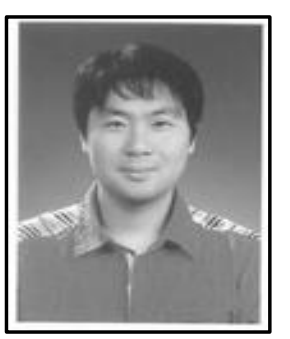

Sungchol Cho, received the M.S. degree in Computer \& Information Communication Engineering from Konkuk University in 2007. Now he is with Konkuk University doing Ph.D. in Computer Science and Engineering. His research fields include Sensor Network, Mobile Network, QoE Network etc. 